\title{
MACULAR CORNEAL DYSTROPHY TYPE II: MULTIPLE STUDIES ON A CORNEA WITH LOW LEVELS OF SULPHATED KERATAN SULPHATE
}

\author{
ANDREW J. QUANTOCK ${ }^{1}$, NIGEL J. FULLWOOD ${ }^{2}$, EUGENE J.-M. A. THONAR ${ }^{3}$, \\ STEPHEN R. WALTMAN ${ }^{4}$, MALCOLM S. CAPEL ${ }^{5}$, MITSUTOSHI ITO ${ }^{1}$, \\ STEVEN M. VERITY ${ }^{1}$ and DAVID J. SCHANZLIN ${ }^{1 *}$ \\ St Louis, Lancaster, Chicago, Belleville and New York
}

\begin{abstract}
SUMMARY
We investigated an individual macular corneal dystrophy (MCD) type II cornea from a 42-year-old woman with markedly reduced antigenic keratan sulphate levels. A characteristic 4.6 ̊ X-ray reflection was evident, and the mid-stroma contained $30 \%$ less sulphur than normal. Close packing of collagen was restricted to the superficial stroma. Abnormally large proteoglycan filaments were noted throughout the extracellular matrix and Descemet's membrane's posterior non-banded zone, but not its anterior banded zone. Small, collagen-associated stromal proteoglycans were susceptible to digestion with chondroitinase $\mathrm{ABC}$, but not keratanase I or N-glycanase. On occasion, collagen fibrils ranged in size from $20 \mathrm{~nm}$ to $58 \mathrm{~nm}$, with preferential diameters of $34 \mathrm{~nm}$ and $42 \mathrm{~nm}$. Corneal guttae were evident, as were numerous endothelial inclusions, most probably due to intracellular fibrillogranular vacuoles similar to those found in the stroma. The endothelium expressed reduced anti-keratan sulphate labelling.
\end{abstract}

Macular corneal dystrophy (MCD) is an autosomal recessive disorder, clinically typified by stromal clouding and the presence of small, scattered opacities in the central superficial cornea. ${ }^{1.2}$ The

From: ${ }^{1}$ Anheuser-Busch Eye Institute, Department of Ophthalmology, Saint Louis University School of Medicine, St Louis, Missouri, USA; ${ }^{2}$ Division of Biological Sciences, Lancaster University, Lancaster, UK; ${ }^{3}$ Departments of Biochemistry and Internal Medicine, Rush-Presbyterian-St Luke's Medical Center. Chicago, Illinois, USA ${ }^{4}$ Green-Waltman Eye Institute, Belleville, Illinois, USA; ${ }^{5}$ National Synchrotron Light Source, Brookhaven National Laboratory, Upton, New York, USA. *Present address: Department of Ophthalmology, University of California at San Diego, La Jolla, California, USA.

Correspondence to: Dr Andrew J. Quantock. Department of Ophthalmology, Kyoto Prefectural University of Medicine, Hirokoji Kawaramachi Kamigyo-ku, Kyoto 602, Japan. Fax: 011-81-75-251-5663. fundamental metabolic defect in MCD seems to be an abnormal synthesis of corneal glycosaminoglycans - a process that is thought to contribute to the progressive corneal opacification. ${ }^{3-10}$

Immunochemical data reveal that MCD is a heterogeneous condition ${ }^{11-13}$ in which the cornea, cartilage and serum in MCD type I patients all contain an unsulphated form of keratan sulphate; these tissues in MCD type II patients, on the other hand, contain normally sulphated keratan sulphate. It is interesting to note that this immunochemical distinction is not evident in the patient's clinical presentation.

Early electron microscopical work on MCD established much of what we now know regarding the histopathology of this condition. ${ }^{14-18}$ More recent histological studies have concerned themselves with establishing the systemic extent of $\mathrm{MCD},{ }^{19}$ and identifying and locating more precisely the abnormal glycosaminoglycan deposits ${ }^{20-22}$ that are known to accumulate in the corneal stroma in MCD. ${ }^{14}$

Over the years many studies of MCD corneas have employed different techniques on different specimens. Here we report, using a single MCD cornea, immunochemical, synchroton X-ray diffraction, electron microscopic immunohistochemical, energy dispersive X-ray microanalysis and electron microscopic histochemical findings. Furthermore, the cornea under investigation may be a member of a new subgroup within the MCD type II population, since antigenic keratan sulphate is present in the patient's serum and cornea, although only at levels not previously recorded.

\section{Report of a Case}

A 40-year-old woman complained of blurred vision and sensitivity to light in both eyes. She noted that 
her symptoms had become progressively worse over the previous 2 years. Her past medical history was unremarkable and she denied any family history of any significant medical or ocular problems. Best corrected visual acuity was 20/200 in her left eye and $20 / 60$ in her right. Slit-lamp examination was significant for diffuse haze with a ground-glass appearance and superficial-to-anterior grey-white pleomorphic opacities with indistinct edges. The opacities were diffusely distributed but were more prominent centrally. No epithelial erosions were evident and the stroma appeared thin and compact. Corneal tissue from the left eye of this patient was obtained for examination at the time of phakic penetrating keratoplasty.

Routine histopathological investigation confirmed the diagnosis of MCD. The corneal epithelium was regular, with Bowman's layer focally disrupted by a deposit of pale, finely granular material. Similar material was also evident in the stroma, where it was variably periodic acid-Schiff positive, but did not stain with trichrome stains. Alcian blue stain for acid mucopolysaccharide was positive.

\section{MATERIALS AND METHODS}

Immediately following removal of the $8-\mathrm{mm}$ diameter corneal button, several segments were excised and processed for routine histopathology, electron microscopic immunohistochemistry, energy dispersive X-ray microanalysis, and electron microscopic histochemistry. The remainder of the tissue was frozen and stored for the synchrotron X-ray diffraction experiments, immunochemical evaluation and enzyme digestions prior to electron microscopic histochemistry.

\section{Synchrotron X-ray Diffraction}

Synchrotron $X$-ray diffraction patterns were obtained on beamline X12 $(\lambda=0.949 \AA)$ at the National Synchrotron Light Source, Brookhaven National Laboratory, USA, ${ }^{23}$ using a specimen-todetector distance of $350 \mathrm{~mm}$ and an exposure time of 5 minutes. The MCD corneal portion was thawed, placed between two Mylar windows in a specially constructed cell holder and exposed to the X-ray beam. A cornea from a 78-year-old with no history of ocular problems was treated identically.

\section{Immunochemical Evaluation}

The frozen MCD corneal specimen was thawed and solubilised by treatment with papain at $60^{\circ} \mathrm{C}$. The concentration of antigenic keratan sulphate was then measured by a previously described enzyme-linked immunosorbent assay (ELISA) which uses the 1/20/5-D-4 monoclonal antibody specific for a highly sulphated epitope on keratan sulphate chains. ${ }^{24}$ The concentration of total glycosaminoglycans in the digest was measured by the dimethylmethylene blue method. ${ }^{25}$ The concentration of collagen in the papain digest was measured by a colorimetric assay, as described previously. ${ }^{26}$ Serum from our patient was also analysed for antigenic keratan sulphate.

\section{Energy-Dispersive $X$-ray microanalysis}

Several slices (100-200 $\mu \mathrm{m}$ thick) were cut through the corneal stroma of the MCD specimen and a normal cornea. These sections were mounted with carbon cement onto aluminium stubs, air-dried and coated with approximately $40 \mathrm{~nm}$ of aluminium by evaporation from a tungsten filament at a vacuum of $5 \times 10^{-5}$ torr $\left(7 \times 10^{-3} \mathrm{kPa}\right) . \mathrm{MCD}$ and normal specimens were mounted on the same stub, coated with aluminium and analysed in a JEOL 840a scanning electron microscope with an 860 Series II Link microanalysis system and a Link systems energy-dispersive detector (detector area $=30 \mathrm{~mm}^{2}$, $8 \mu \mathrm{m}$ thick beryllium window). During the analysis the following conditions were used: accelerating voltage $15 \mathrm{kV}$, probe current $0.5 \mathrm{nA}$, working distance $34 \mathrm{~mm}$, X-ray detector working distance 25 $\mathrm{mm}$, analysis area $400 \mu \mathrm{m}^{2}$, pre-set livetime 100 seconds, take-off angle $45^{\circ}$. Fourteen mid-stromal areas were analysed from each sample. Since MCD and normal specimens were mounted side by side and coated in tandem, counts from the aluminium coating were used as an internal standard.

\section{Electron Microscopic Immunohistochemistry}

Immediately following surgery, portions of the MCD cornea were fixed for 48 hours at room temperature in $4 \%$ paraformaldehyde, $0.1 \%$ glutaraldehyde in phosphate-buffered-saline (PBS) buffer. Portions of a normal cornea - post-mortem from a 67-year-old donor with no history of ocular probiems - were treated identically. Labelling was carried out on the normal and MCD corneas simultaneously. Following fixation the samples were thoroughly washed in PBS buffer and incubated at room temperature with undiluted, normal goat serum for 20 minutes. The goat serum was removed and the corneal endothelium incubated for 2 hours at room temperature with the primary antibody (5-D-4; ICN Biochemicals, UK) that recognises a highly sulphated region of the keratan sulphate chain (1:100 dilution in PBS buffer, $\mathrm{pH} 7.4$, containing $1 \%$ bovine serum albumin (BSA) and $1 \%$ Tween 20). This incubation was followed by a 30 minute wash under agitation in three changes of the buffer. To visualise the primary antibody, samples were incubated in goat anti-mouse $\operatorname{IgG}$ conjugated to $5 \mathrm{~nm}$ gold particles (British Biocell International, UK) for 2 hours at a dilution of $1: 100$ in PBS, $\mathrm{pH} 8.5$, containing $0.5 \% \mathrm{BSA}, 0.5 \%$ normal goat serum, $1 \%$ sodium chloride, $1 \%$ fish gelatin and $1 \%$ Tween 20. This secondary incubation was 
followed by at least three 30 minute washes in the buffer and five 5 minute washes in distilled water. For controls the 5-D-4 antibody was replaced by an equivalent concentration of mouse ascites fluid (Sigma, UK).

The immunolabelled corneal samples were silver enhanced (using a kit from British Biocell International, UK) for 5-10 minutes at room temperature and washed in distilled water. They were then postfixed in $2 \%$ glutaraldehyde, dehydrated through a graded alcohol series to $100 \%$ ethanol and air-dried before being mounted, endothelial side up, and sputter-coated with gold. The specimens were examined at $15 \mathrm{kV}$ in a JEOL 840a scanning electron microscope.

\section{Enzyme Digestions Prior To Electron Microscopic Histochemistry}

Three small, full-thickness corneal portions $\left(\approx 1 \mathrm{~mm}^{2}\right)$ were dissected from the centre of the frozen portion of the MCD cornea, thawed and lightly fixed for 25 minutes at $4{ }^{\circ} \mathrm{C}$ in $2.5 \%$ formalin in a $25 \mathrm{mM}$ sodium acetate buffer. Following a brief wash in the enzyme buffer the specimens were digested with either chondroitinase ABC (2.5 units/ $\mathrm{ml}$ ) (Sigma, St Louis, MO), $n$-glycanase (5 units $/ \mathrm{ml}$ ) (Genzyme, Cambridge, MA) or keratanase I (endo$\beta$-galactosidase from Pseudomonas; $1 \mathrm{unit} / \mathrm{ml}$ ) (Sigma, St Louis, MO). The corneal specimens were incubated for 5 hours at $40{ }^{\circ} \mathrm{C}$ in the respective enzymes in a Tris $(0.25 \mathrm{M})$ buffer containing $0.5 \mathrm{mg} /$ $\mathrm{ml}$ BSA, $0.33 \mathrm{M}$ sodium acetate, $0.5 \mathrm{M}$ sodium chloride, $0.01 \%$ type II-S soybean trypsin inhibitor, 5 $\mathrm{mM}$ acid-free EDTA and $2.5 \mathrm{mM}$ benzamidine, $\mathrm{pH}$ 8.0. ${ }^{20}$ Following enzyme incubation and three 5 minute washes in the Tris buffer the specimens were processed for electron microscopic histochemistry as outlined below.

\section{Electron Microscopic Histochemistry}

Immediately following surgery (and following enzyme incubations) MCD corneal tissue was fixed, stained for proteoglycans with Cuprolinic blue, dehydrated and embedded as described previously. ${ }^{20,27}$ Ultrathin sections (silver/gold) were positively stained for collagen with $1 \%$ aqueous phosphotungstic acid followed by $2 \%$ aqueous uranyl acetate, and examined in a JEOL 1200EX microscope (JEOL, Peabody, MA) calibrated with a 2160 lines/mm grating replica. The diameter distribution of collagen fibrils $(n=800)$ within $1 \mu \mathrm{m}$ of a deposit of fibrillogranular vacuoles was quantified by measuring 100 fibrils on eight separate micrographs taken at a magnification setting of $\times 50000$.

\section{RESULTS \\ Synchrotron $X$-ray Diffraction}

The high-angle synchrotron $X$-ray diffraction pattern from our patient's MCD cornea, like patterns from the normal human cornea, contained a $2.9 \AA$ collagen meridional reflection, a diffuse reflection due to water scatter, a reflection from the Mylar windows of the cell holder, and a reflection that arises due to the fairly regular, parallel arrangement of the collagen molecules that constitute the stromal collagen fibrils. In addition, the synchrotron X-ray diffraction pattern from the MCD cornea contained a sharp, intense reflection due to a periodic repeat of $4.6 \AA$ that was not present on the pattern from the normal human cornea.

\section{Immunochemical Evaluation}

Sulphated keratan sulphate was detected in our patient's cornea and serum, although at levels well below normal. The content of corneal keratan sulphate (as a percentage of collagen + total proteoglycan) was $0.34 \%$ compared with $3.58 \%$ from a normal human cornea analysed in the same experiment. Similarly, our patient's serum keratan sulphate level of $19 \mathrm{ng} / \mathrm{ml}$ was well below the published values of $251 \pm 78 \mathrm{ng} / \mathrm{ml}^{28}$ and $268 \pm 133$ $\mathrm{ng} / \mathrm{ml}^{29}$ for normal adult populations, and is the lowest value ever recorded by one of us (E.J.M.A.T.) in an analysis of over 1000 sera from individuals without MCD type I (data not shown).

\section{Energy-Dispersive X-ray Microanalysis}

Sulphur was the only element detected in significant quantities in both the normal and MCD corneal specimens. Sodium, phosphorus and calcium were all present, but only at concentrations near the detection limit of the X-ray microanalysis system. The MCD specimen had, on average, $30 \%$ fewer X-ray counts for sulphur than were obtained from the normal corneal sample. Statistical analysis revealed that this difference was highly significant $(p<0.0001)$.

\section{Histochemistry and Immunohistochemistry}

The general appearance of the cornea was in many ways consistent with the classic MCD histopathology. Several features, however, warrant attention.

The close packing of normal-diameter collagen fibrils was marked, and restricted to a region of the superficial stroma between about $20-40 \%$ depth (Fig. 1). Above and below this, localised regions of the collagen matrix were in disarray (Fig. 2). Abnormally large, Cuprolinic-blue-stained proteoglycan filaments were present in the MCD stroma, where they were often associated with localised fibrillar disruptions (Fig. 2). They were also present within deposits of fibrillogranular vacuoles, where they generally existed at the peripheries of individual 
fibrillogranular vacuoles (Fig. 3). Previous work with MCD has indicated that this type of large, Cuprolinic-blue-stained filament contains a chondroitin sulphate/dermatan sulphate component; ${ }^{20,21}$ however, in the present case such filaments proved resistant to incubation with keratanase I, $N$-glycanase and chondroitinase ABC. Electron-lucent lacunae were evident throughout our patient's stroma (Fig. 4) and, occasionally, we observed several strands of amorphous material that protruded into the collagen matrix from a characteristic

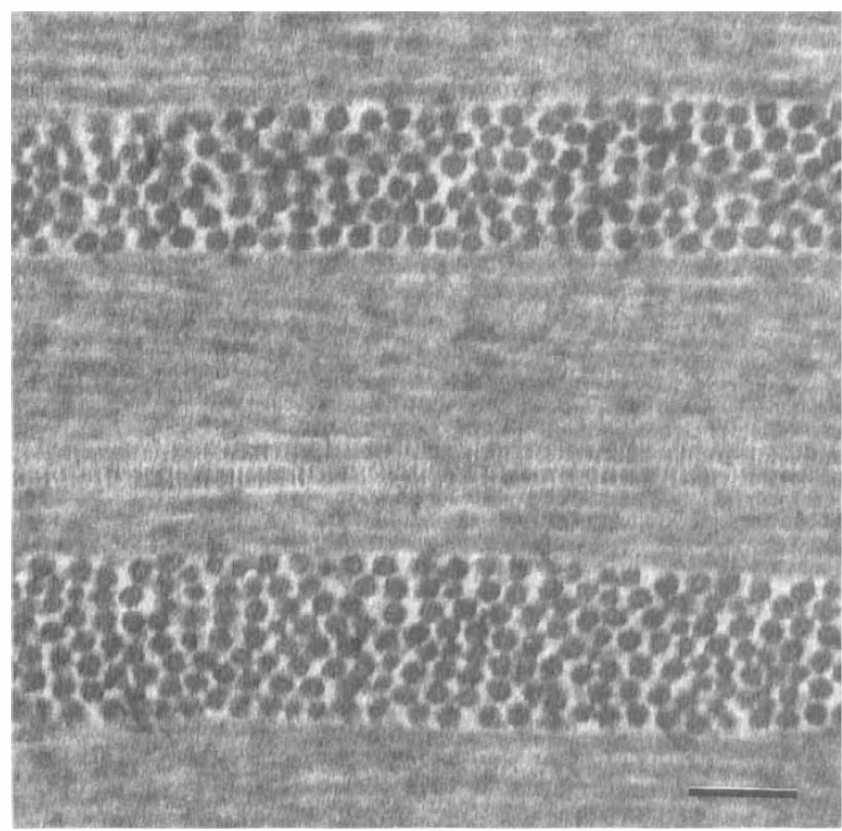

Fig. 1. Close packing of collagen fibrils in the superficial cornea between approximately $20 \%$ and $40 \%$ of the stromal depth. Scale bar represents $100 \mathrm{~nm}$.

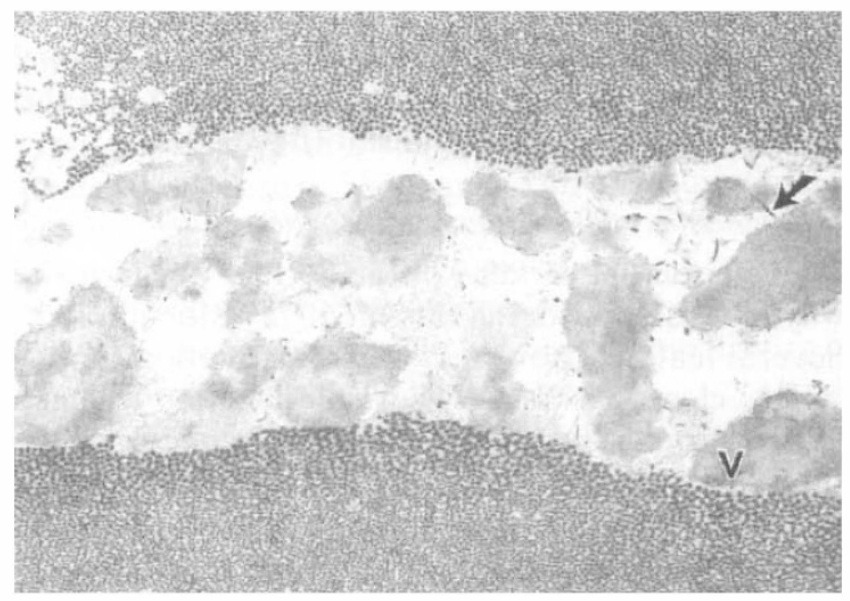

Fig. 3. A characteristic MCD deposit of fibrillogranular vacuoles with abnormally large proteoglycan filaments (arrow) associated with the peripheries of individual vacuoles $(V)$. The collagen fibrils in close proximity to both sides of this deposit are clearly larger than the more distant fibrils. Scale bar represents $500 \mathrm{~nm}$. deposit of fibrillogranular MCD vacuoles; the outline of these strands was somewhat reminiscent of the outline of cellular processes (Fig. 4).

Away from the disrupted regions of the tissue, much of the stromal architecture was fairly unremarkable, although often the association of orthogonal proteoglycans with the collagen fibrils was observed to be more periodic than is common in a normal human stroma (Fig. 4). These 'small' stromal proteoglycans remained in the tissue following digestion with keratanase I and $N$-glycanase, but

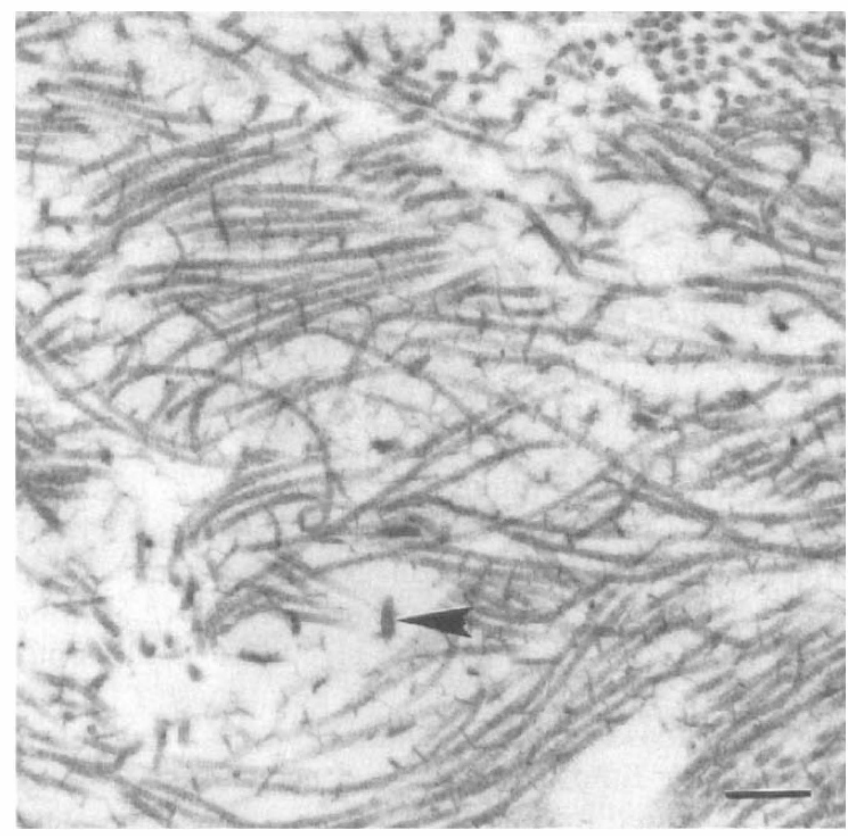

Fig. 2. A localised region of the macular corneal dystrophy (MCD) stroma where the fibrillar organisation of the stroma is in disarray and some large proteoglycan filaments are evident (arrowhead). Scale bar represents $200 \mathrm{~nm}$.

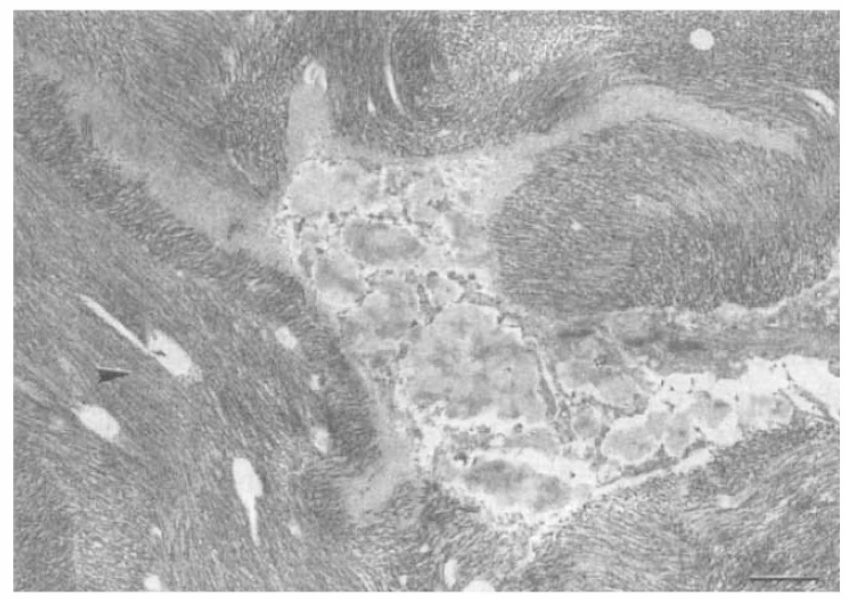

Fig. 4. A characteristic MCD deposit of fibrillogranular vacuoles with appendages of amorphous material that resemble cellular processes. The stromal proteoglycans in the surrounding tissue often display an unusually periodic association with the stromal collagen (arrowhead). Scale bar represents $1 \mu \mathrm{m}$. 

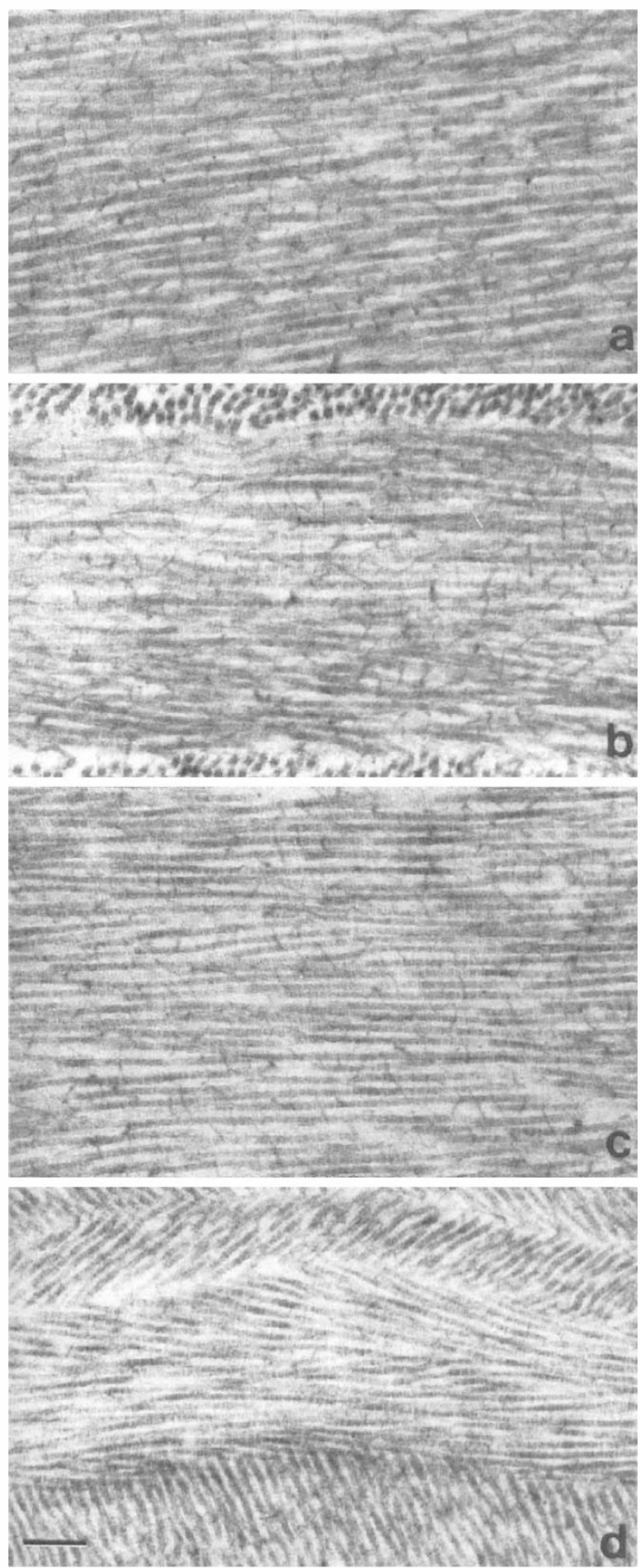

Fig. 5. Relatively undisturbed regions of the MCD stromal matrix without enzyme treatment (a), and following incubation of the tissue with (b) keratanase I, (c) N-glycanase and (d) chondroitinase $A B C$. The virtual absence of stromal proteoglycans following chondroitinase $A B C$ digestion indicates that they contained chondroitin/dermatan sulphate side chains. Scale bar represents $200 \mathrm{~nm}$.

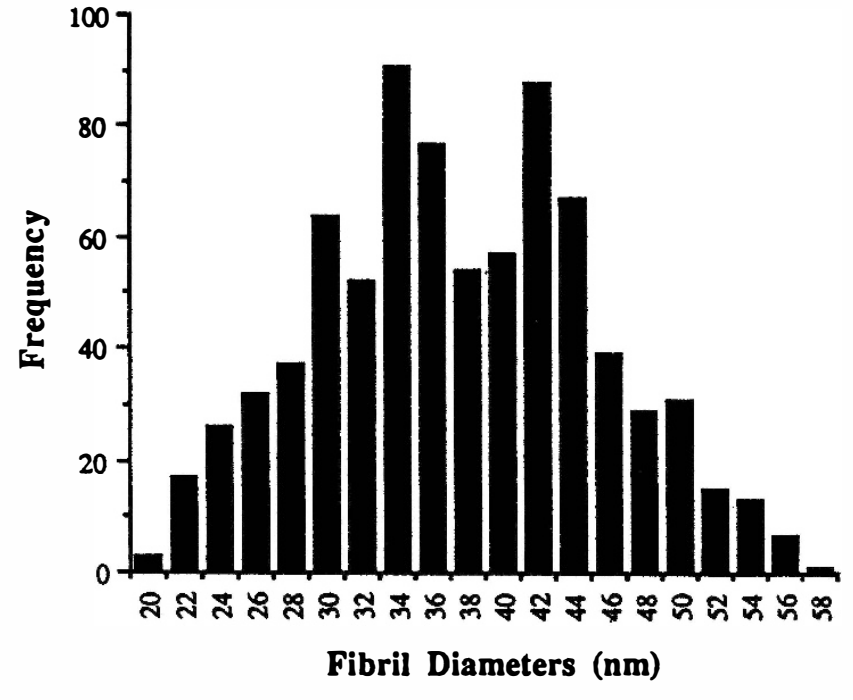

Fig. 6. The frequency distribution of collagen fibril diameters in a region of the tissue adjacent to a deposit of fibrillogranular vacuoles such as that observed in Fig. 3. The corresponding value for collagen fibrils in normal human corneas is $26.0 \mathrm{~nm}(S D \pm 2.4 \mathrm{~mm}){ }^{34}$

were virtually absent following the cornea's incubation with chondroitinase $\mathrm{ABC}$ (Fig. 5).

In many areas of the tissue adjacent to fibrillogranular deposits a remarkable variation in the diameter of the collagen fibrils was evident (Fig. 3). When quantified, the diameters of the collagen fibrils $(n=800)$ within $1 \mu \mathrm{m}$ of a deposit of fibrillogranular vacuoles were found to range from $20 \mathrm{~nm}$ to $58 \mathrm{~nm}$. The graphical representation of these data (Fig. 6) suggested a bimodal frequency distribution with relatively large numbers of collagen fibrils tending to have diameters of $34 \mathrm{~nm}$ and $42 \mathrm{~nm}$.

The surface topography of the posterior face of Descemet's membrane in the MCD cornea was porous, with numerous $100-500 \mathrm{~nm}$ diameter holes visible over its surface (Fig. 7). This was in stark contrast to the featureless morphology of the corresponding area of the normal Descemet's membrane (Fig. 7). Furthermore, when a cross-section of Descemet's membrane from the MCD cornea was examined, holes or pores similar to those observed on the posterior face of Descemet's membrane could be seen to persist deep into the membrane, but not to the stromal boundary (Fig. 8). Examination of an identically prepared sample of Descemet's membrane from normal human cornea confirmed that such holes are not a normal feature of the membrane (Fig. 8).

Transmission electron microscopical images of the posterior MCD cornea (Fig. 9) revealed that the pores in the posterior portion of Descemet's membrane that were evident on scanning electron microscopic examination contained Cuprolinic-bluestained proteoglycan filaments similar to the large ones seen in the stroma. These macromolecules were resistant to digestion with keratanase I, $N$-glycanase 


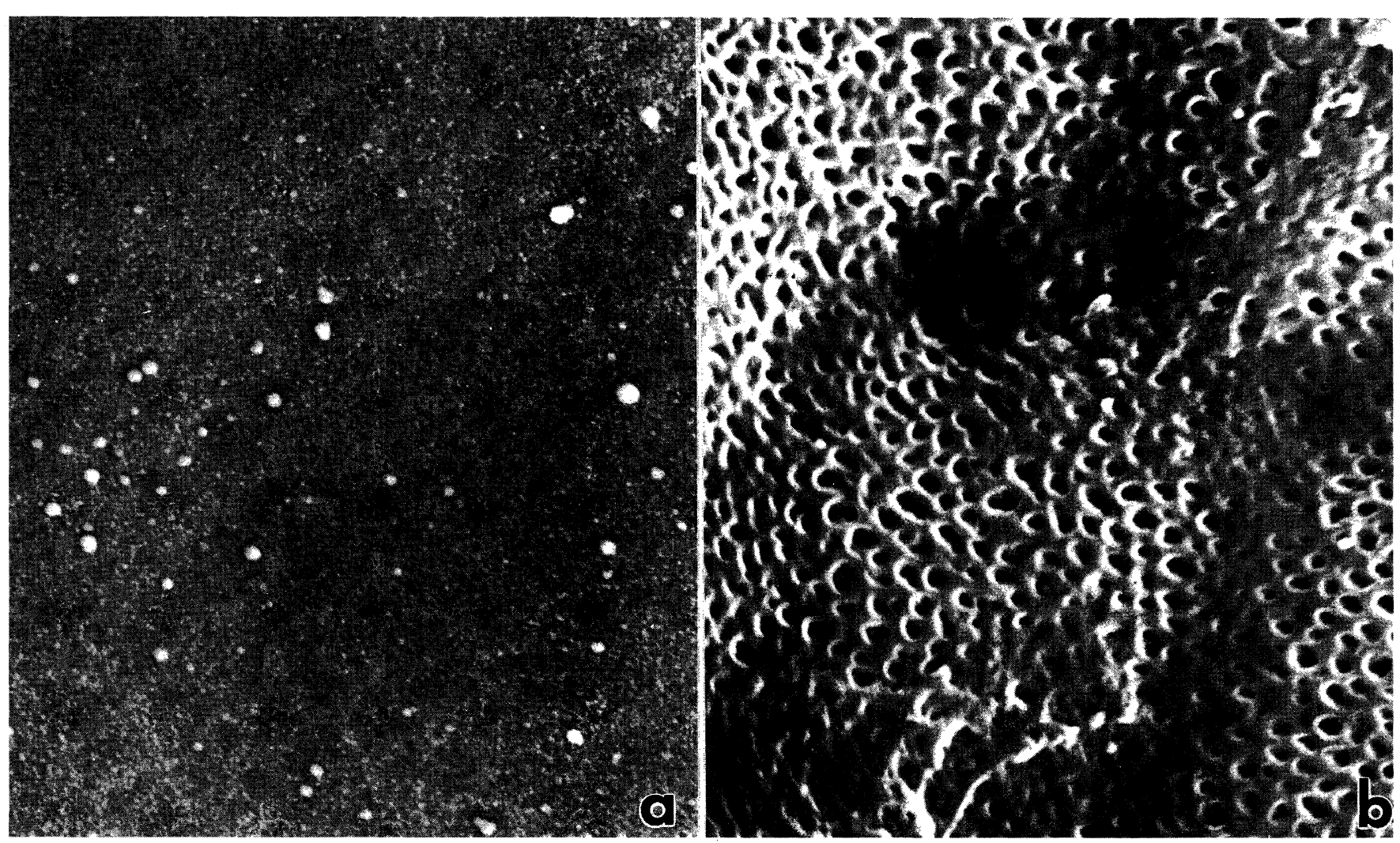

Fig. 7. The exposed endothelial face of Descemet's membrane from (a) a normal human cornea and $(b)$ our MCD patient's cornea. At this magnification the posterior face of Descemet's membrane from the normal cornea appears featureless apart from some surface debris. On the other hand, the exposed surface of Descemet's membrane from the MCD cornea is covered by numerous holes or pores. Magnification $\times 10000$.
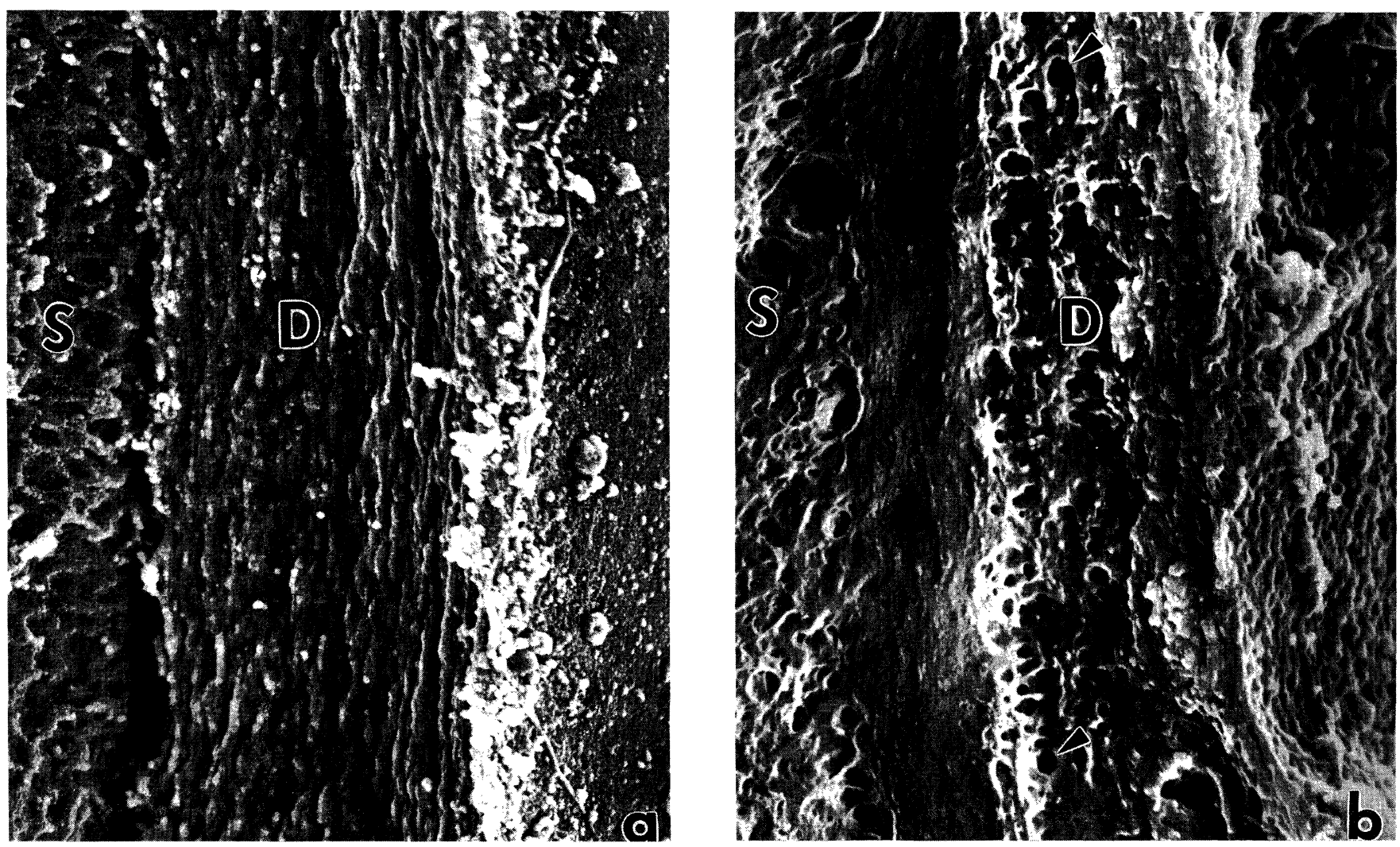

Fig. 8. An oblique cross-section through Descemet's membrane from (a) a normal human cornea and (b) our MCD patient's cornea. The most posterior region of the corneal stroma is also visible. The ultrastructure of Descemet's membrane in the $M C D$ case is clearly abnormal, with the pores (arrowed) in Descemet's membrane confined to its posterior portion. S, stroma; $D$, Descemet's membrane. Magnification $\times 7000$. 


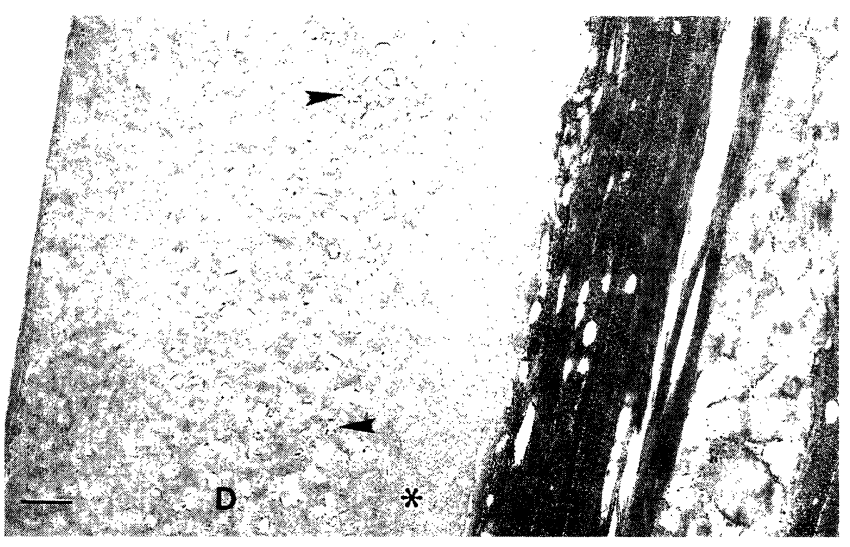

Fig. 9. Electron-lucent lacunae are visible in the posterior $M C D$ stroma, as is a deposit of fibrillogranular vacuoles/ large proteoglycan filaments. The morphology of Descemet's membrane's anterior banded zone is unremarkable (asterisk). The pores in the posterior non-banded zone of Descemet's membrane are seen to contain large sulphated proteoglycan filaments similar to those observed in the stroma (arrowheads). This micrograph is of the MCD tissue following incubation in $\mathrm{N}$-glycanase. The features described are identical to those observed in the MCD tissue without enzyme incubation or following keratanase I or chondroitinase $A B C$ incubation (data not shown). D, Descemet's membrane; $S$, stroma. Scale bar represents $1 \mu \mathrm{m}$.
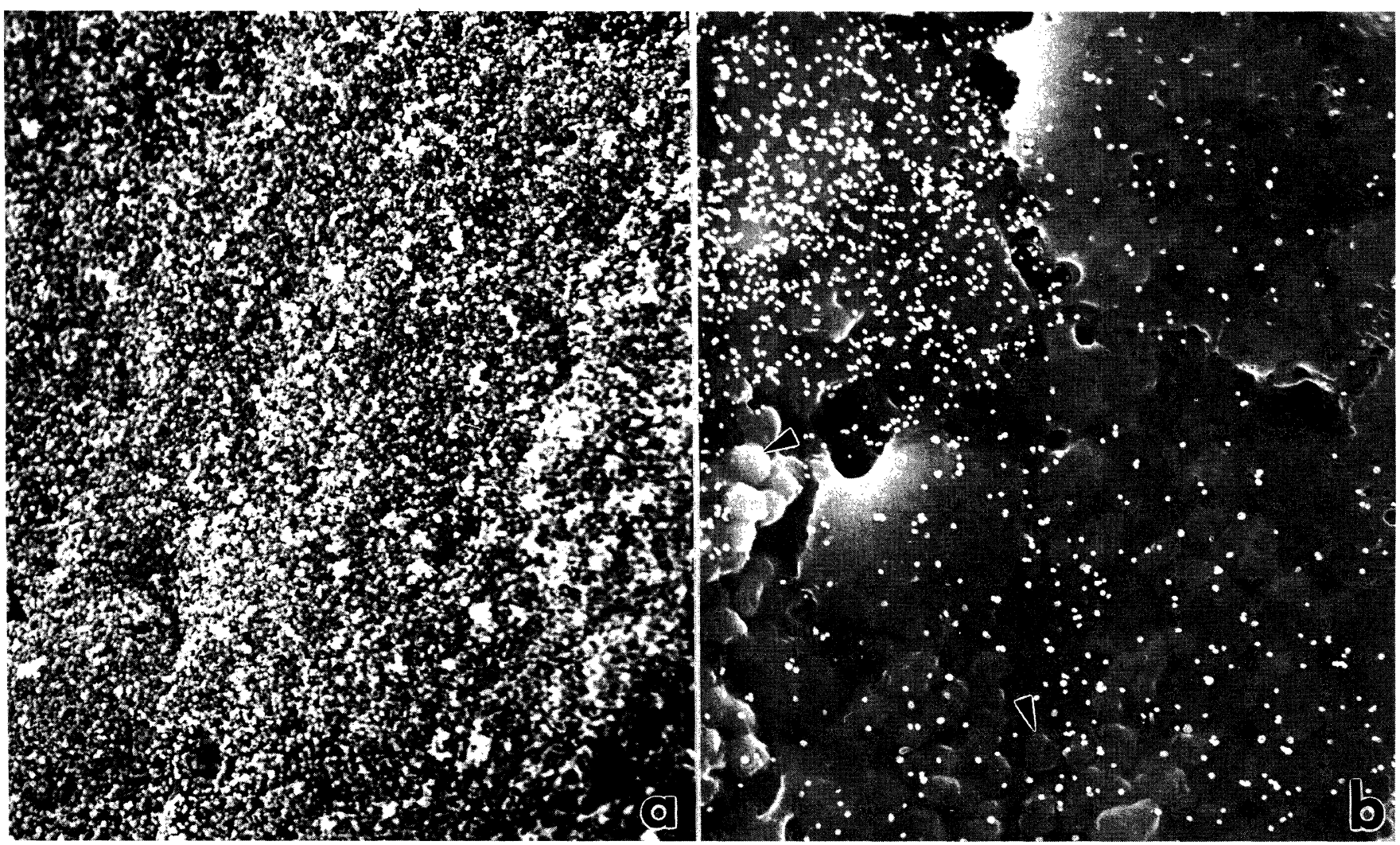

Fig. 10. The apical surface of (a) normal and (b) MCD corneal endothelial cells immunolabelled for keratan sulphate. The silver-enhanced gold label is visible as bright dots. The surfaces of the normal endothelial cells are completely covered by the label, and the distribution of the label appears even over the surface of individual cells. The amount of labelling is much lower on the endothelium of the MCD cornea. Furthermore, the morphology of the MCD endothelial cells appears abnormal, with the outline of numerous cellular inclusions visible (arrowhead). Magnification $\times 3000$.

and chondroitinase ABC. Also, corneal guttae were present and fibrillogranular vacuoles - several hundred nanometres across and similar to those observed in the stroma - were often present, either individually or in groups, in the endothelial cells (data not shown).

The endothelial cells from the MCD cornea, when viewed on the scanning electron microscope, had a wider range of cell sizes than is usual for normal corneal specimens imaged by the same method (Fig. 10). When the surface of individual MCD endothelial cells was examined, the outline of numerous large cellular inclusions could be resolved. These inclu- sions ranged in size from $100 \mathrm{~nm}$ to $1000 \mathrm{~nm}$ across; they were evident in many, but not all, of the endothelial cells from the MCD cornea, but in none of the cells in the normal cornea (Fig. 10). In the normal human cornea keratan sulphate labelling was ubiquitous over the surface of the endothelium (Fig. 10). In addition, although labelling over the surface of individual endothelial cells was invariably homogeneous, the amount of labelling varied considerably between different cells in the same specimen. In contrast, the MCD endothelium exhibited relatively low levels of labelling for antigenic keratan sulphate (Fig. 10). 


\section{DISCUSSION}

The work of Thonar, Klintworth and colleagues ${ }^{28.29}$ makes it clear that our MCD type II patient's serum keratan sulphate level of $19 \mathrm{ng} / \mathrm{ml}$ is remarkably low (lower than any level recorded in over 1000 nonMCD type I patients by E.J.-M.A.T.) as is the amount of sulphated keratan sulfate in her cornea $(0.34 \%$ keratan sulphate as opposed to $3.58 \%$ keratan sulphate in a normal cornea measured as a percentage of collagen + total proteoglycan). Normally, the cornea and serum of MCD type I patients contain sulphated keratan sulphate at levels below the detection limit of the ELISA (approximately $3 \mathrm{ng} / \mathrm{ml}$ ). MCD type II patients, on the other hand, generally possess levels of serum and corneal keratan sulphate that are within the range for normal individuals. Thus, the finding of a MCD type II patient with dramatically reduced, but detectable, amounts of sulphated keratan sulphate in her serum and cornea raises some interesting questions regarding the current classification of MCD. It seems that, based on immunochemical findings, a heterogeneity may exist within the MCD type II subgroup. Also, since most of the antigenic keratan sulphate in serum is derived from cartilage, the present correlation between the levels of antigenic keratan sulphate in our patient's cornea and serum lends support to the idea $^{19}$ that the abnormality in the sulphation of keratan is systemic.

In recent years we have observed a $4.6 \AA$ reflection on synchrotron X-ray diffraction patterns from 11 different MCD corneas from different pedigrees, and we know that both MCD type I corneas and MCD type II corneas with normal levels of antigenic keratan sulphate are able to produce the $4.6 \AA$ $\mathrm{X}$-ray reflection. ${ }^{30,31}$ To date no other human cornea - normal or pathologic - has been studied that contains a periodic $4.6 \AA$ ultrastructure that gives rise to a high-angle synchrotron $\mathrm{X}$-ray reflection. ${ }^{21.30 .32-34}$ We have now observed the $4.6 \AA \mathrm{ACD}$ reflection on $\mathrm{X}$-ray diffraction patterns obtained from MCD type II patients with serum keratan sulphate levels as disparate as $390 \mathrm{ng} / \mathrm{ml}^{22}$ and $19 \mathrm{ng} / \mathrm{ml}$ (present study), indicating that the levels of sulphated keratan sulphate in MCD type II corneas do not influence the appearance of the $4.6 \AA$ reflection.

Recent work suggests that, in MCD type I and II corneas, the abnormal sulphation pattern of both the keratan sulphate glycosaminoglycans and the chondroitin/dermatan sulphate glycosaminoglycans underlies the appearance of the $4.6 \AA$ X-ray reflection. ${ }^{31}$ This contention has found some indirect support in the recent discovery of a $4.6 \AA$ X-ray reflection in scarred rabbit corneas. ${ }^{35}$ Apart from MCD corneas, these are the only other types of cornea known to give rise to a $4.6 \AA \mathrm{X}$-ray reflection; they also possess an abnormally sulphated proteoglycan population. ${ }^{36}$

Energy-dispersive $\mathrm{X}$-ray microanalysis indicates that the mid-stroma of our MCD patient's cornea contains low levels of sulphur. This finding is consistent with the decreased sulphation of the keratan chains as documented by our immunochemical studies; we do not know, however, whether the low levels of antigenic keratan sulphate are reflective of the decreased sulphation of all keratan chains or the total lack of sulphation of some of the keratan chains and the normal sulphation of others. Nevertheless, these data do make it clear that, in this particular patient, any oversulphation of the chondroitin/dermatan sulphate glycosaminoglycans that might occur is not sufficient to compensate for the low sulphation of the keratan chains.

Our previous low-angle synchrotron X-ray diffraction experiments on MCD type I cornea near physiological hydration ${ }^{21}$ taught us that the average spacing of normal diameter collagen fibrils in the bulk of the stroma is approximately $22 \%$ lower than normal. On the face of it, a reduction in the interfibrillar collagen spacing of this extent, if it were uniform, would seem to account for the clinical observation that MCD corneas of undetermined subtype are typically $20 \%$ thinner than normal. ${ }^{37,38}$ However, in the present case our patient's cornea contains a region of the tissue (between about $20 \%$ and $40 \%$ of the stromal depth) where the collagen fibrils are highly compacted (Fig. 1). This indicates that the close packing of collagen in MCD not only varies as a function of the lateral position within the stroma, ${ }^{21}$ but also can be heterogeneous with respect to stromal depth.

The abnormally-large, Cuprolinic-blue-stained proteoglycan filaments throughout the extracellular matrix and at the peripheries of extracellular fibrillogranular vacuoles in our patient's cornea were not digested by: (i) keratanase I, an endoenzyme that releases the keratan sulphate chains from the core protein and degrades the less highly sulphated regions of corneal keratan sulphate into small oligosaccharides, (ii) $\mathrm{N}$-glycanase, an enzyme that cleaves asparagine-linked carbohydrate chains at $\beta$-aspartylglycosylamine bonds and thus releases otherwise intact keratan sulphate chains from the core protein to which they are covalently bound, or (iii) chondroitinase $\mathrm{ABC}$, an enzyme that degrades chondroitin sulphate/dermatan sulphate chains into their constituent disaccharides. Previous studies ${ }^{20.21}$ indicated that most of the large proteoglycan filaments were removed from the stroma of $\mathrm{MCD}$ corneas by incubation with chondroitinase $\mathrm{ABC}$, and thus were assumed to contain a chondroitin sulphate/ dermatan sulphate component that was accessible to 
the enzyme. It is not clear why, in this case, the large proteoglycans were not digested by the aforementioned enzymes, although it is worth considering the possibility that it may have been because the large proteoglycan filaments that we observe are formed by an interaction between chondroitin sulphate/ dermatan sulphate glycosaminoglycans and keratan sulphate glycosaminoglycans that some authors ${ }^{10.31}$ believe is possible. Such an interaction could well render suitable enzyme cleavage sites inaccessible.

Even though the stromal disruptions in this MCD cornea were extensive, several localised areas of structurally normal stroma were evident. The stromal proteoglycans in many of these areas, however, appeared to associate with the collagen fibrils in a periodic manner (Fig. 4) more akin to bullous keratopathy specimens than normal human cornea. ${ }^{39}$ Because different proteoglycans possess the ability to bind to specific but different locations in the collagen D-period repeat ${ }^{40}$ - keratan sulphate at the 'a' and ' $c$ ' staining bands, and chondroitin sulphate/dermatan sulphate at the ' $\mathrm{d} / \mathrm{e}$ ' staining bands - a periodic distribution of proteoglycans along extended distances is rarely seen with a mix of collagen-associated proteoglycans. Our suspicion that keratan sulphate proteoglycans were lacking in this case was confirmed by the enzyme digestions (Fig. 5); these indicated that the small, collagen-associated proteoglycans in the MCD cornea contained chondroitin sulphate/dermatan sulphate side chains.

Unlike normal human corneas, whose collagen fibrils when prepared for electron microscopy using the method described herein and viewed in crosssection invariably measure $26.0 \mathrm{~nm} \quad(n=1000$; $\left.\mathrm{SD}= \pm 2.4 \mathrm{~nm}^{34}\right)$, MCD collagen fibrils in close proximity to deposits of extracellular fibrillogranular vacuoles were often abnormally large (Fig. 3). Large stromal collagen fibrils are a feature of several diseases of the cornea, and have been documented (but not quantified) in localised regions of a MCD type II cornea. ${ }^{22}$ The range of collagen fibril diameters in the aforementioned MCD study ${ }^{22}$ $(25-60 \mathrm{~nm})$ corresponds well with the present data that show collagen fibrils within $1 \mu \mathrm{m}$ of a deposit of fibrillogranular vacuoles to measure between $20 \mathrm{~nm}$ and $58 \mathrm{~nm}$. Moreover, when our present data are visualised graphically (Fig. 6), it seems that relatively high numbers of collagen fibrils tend to have diameters in the region of $34 \mathrm{~nm}$ and $42 \mathrm{~nm}$. A similar quantification of the collagen fibrils in Scheie's syndrome ${ }^{34}$ and Hurler's syndrome ${ }^{41}$ where their diameters range from $20 \mathrm{~nm}$ to $52 \mathrm{~nm}$ and from $13 \mathrm{~nm}$ to $50 \mathrm{~nm}$ respectively - has also provided some evidence for a bimodal distribution of collagen fibril diameters. In these cases the more frequently occurring collagen fibril diameters tended to be $28 \mathrm{~nm}$ and $36 \mathrm{~nm}$ (Scheie's syndrome ${ }^{34}$ ) and
$23.5 \mathrm{~nm}$ and $39.5 \mathrm{~nm}$ (Hurler's syndrome $\mathrm{e}^{41}$ ). The discrepancy between the actual values for the preferred collagen diameters found in the aforementioned corneal studies may be due to the different amounts of tissue shrinkage that can occur in different electron microscopical preparation runs, as highlighted recently by Fullwood and Meek. ${ }^{42}$ However, since we can assume that the data obtained within a single study would be standardised, neither inter-study tissue preparation differences nor systematic measurement errors would be expected to affect the value for the difference between preferred collagen diameters found in each study. These values turn out to be $8 \mathrm{~nm}, 16 \mathrm{~nm}$ and $8 \mathrm{~nm}$ for Scheie's syndrome ${ }^{34}$ Hurlers' syndrome ${ }^{41}$ and MCD (present study) respectively. With this in mind, it is interesting to note that, in 1979, Parry and Craig ${ }^{43}$ presented electron microscopic evidence for an $80 \AA$ unit in collagen fibrils from a variety of fetal, immature and adult tissues including cornea. Their data showed some variation but, in general, collagen fibril diameters tended to cluster around $16 \mathrm{~nm}, 24 \mathrm{~nm}$, $32 \mathrm{~nm}, 40 \mathrm{~nm}$ and $48 \mathrm{~nm}$. It appears, then, that we may be starting to uncover a phenomenon whereby abnormally large collagen fibrils in certain pathological human corneas prefer to increase their diameters in discrete quanta of $8 \mathrm{~nm}$. Since stromal glycosaminoglycans are thought to influence collagen fibrillogenesis, ${ }^{44.45}$ it is worth considering the possibility that abnormal functioning of these molecules in MCD, Scheie's syndrome and Hurler's syndrome may underlie the formation of pockets of large collagen fibrils.

The appearance of Descemet's membrane in our MCD type II patient (Figs. 7, 8) is in line with previous studies that have documented a normal anterior banded zone and a honeycombed posterior non-banded zone. ${ }^{17,18,46}$ In our study, Cuprolinic blue staining revealed that the pores in Descemet's membrane contained large, sulphated proteoglycan filaments not seen in normal Descemet's membrane. They appeared similar in size to those filaments in the stroma (Fig. 9), although their composition remains unknown. In general, the more anterior pores in the posterior zone of Descemet's membrane were larger, better defined and contained larger proteoglycans than the pores closer to the endothelium, although the demarcation between these regions was more gradual than strict. Similar findings - though without the proteoglycan staining - have been reported previously. ${ }^{17,18}$ Since the pores towards the endothelial side of Descemet's membrane do not contain such large proteoglycans as the more well-defined pores in the centre of Descemet's membrane it may well be the case that a congregation of large proteoglycans causes the formation of the pores in Descemet's membrane. Even though we 
can provide no direct evidence as to the origin of these large Descemet's membrane proteoglycans, it seems reasonable to assume that endothelial, rather than stromal, cells synthesise these molecules.

The intracellular inclusions evident in scanning electron micrographs of the posterior face of our MCD type II patient's endothelium (Fig. 10) resemble those reported by Klintworth. ${ }^{1}$ Their location, size and variation in size are all consistent with the assumption that they are due to the intracellular fibrillogranular vacuoles previously documented in MCD endothelial cells ${ }^{17}$ and present in some of our patient's endothelial cells.

Sulphated keratan sulphate is known to be present on the apical surface of human, bovine and rabbit endothelial cells where, recently, its expression has been linked to endothelial cell migration. ${ }^{47}$ In this study we found that the endothelial cell surface of the MCD specimen had much lower levels of labelling for sulphated keratan sulphate than the normal human endothelium (Fig. 10). This finding emphasises the systemic nature of $\mathrm{MCD}$, and suggests that the corneal endothelial cells in our MCD type II patient synthesise low levels of sulphated keratan sulphate. In MCD type I - the variant where no sulphated keratan sulphate is detected immunochemically in the serum or cornea - it is likely that the endothelium expresses no sulphated keratan sulphate, but this remains to be seen. Of course, since the antibody used for immunohistochemistry (5-D-4) recognises only the sulphated form of keratan sulphate, the reduced endothelial labelling in MCD could be due to the presence of an undersulphated form of keratan sulphate.

In conclusion, this patient exhibited many of the classic features of macular corneal dystrophy and provided us with some new insights regarding the histopathology of this intriguing condition.

Research was carried out, in part, at the National Synchrotron Light Source, Brookhaven National Laboratory, which is supported by the US Department of Energy, Division of Materials Sciences and Division of Chemical Sciences (user grant 93-X-729 (A.J.Q.); DOE contract no. DE-AC02-76CH00016). This work was supported by grants EYO4609, AG04736 and AR39239 from the National Institutes of Health, Bethesda, MD, and by funds from Research to Prevent Blindness, New York, NY, and the T.F.C. Frost Trust, London, UK.

Key words: Cornea; Macular corneal dystrophy; Proteoglycans, Glycosaminoglycans.

\section{REFERENCES}

1. Klintworth GK. Disorders of glycosaminoglycans (mucopolysaccharides) and proteoglycans. In: Garner A, Klintworth GK, editors. Pathobiology of ocular disease: a dynamic approach. New York: Marcel Decker, 1994:855-92.
2. Quantock AJ. An erroneous glycosaminoglycan metabolism leads to corneal opacification in macular corneal dystrophy. Glycosylation Dis 1994;1:143-51.

3. Klintworth GK. Research into the pathogenesis of macular corneal dystrophy. Trans Ophthalmol Soc UK 1980;100:186-94.

4. Klintworth GK. Macular corneal dystrophy: a localised disorder of mucopolysaccharide metabolism? Proc Clin Biol Res 1982;82:69-101.

5. Klintworth GK, Smith CF. Macular corneal dystrophy: studies of sulphated glycosaminoglycans in corneal explant and confluent stromal cell cultures. Am J Pathol 1977;89:167-82.

6. Klintworth GK, Smith CF. Abnormal product of corneal explants from patients with macular corneal dystrophy. Am J Pathol 1980;101:143-57.

7. Klintworth GK, Smith CF. Abnormalities of proteoglycans synthesised by corneal organ cultures derived from patients with macular corneal dystrophy. Lab Invest 1983;48:603-12.

8. Hassell JR, Newsome DA, Krachmer JH, Rodrigues M. Macular corneal dystrophy: failure to synthesise a mature keratan sulphate proteoglycan. Proc Natl Acad Sci USA 1980;77:3705-9.

9. Hassell JR, Newsome DA, Nakazawa K, Rodrigues M, Krachmer JH. Defective conversion of a glycoprotein precursor to keratan sulphate proteoglycan in macular corneal dystrophy. In: Hacks S, Wang J, editors. Extracellular matrix. New York: Academic Press, 1982:397-406.

10. Nakazawa K, Hassell JR, Hascall VC, Lohmander S, Newsome DA, Krachmer J. Defective processing of keratan sulphate in macular corneal dystrophy. J Biol Chem 1984;259:13751-7.

11. Yang CJ, SundarRaj N, Thonar EJ-MA, Klintworth GK. Immunohistochemical evidence of heterogeneity in macular corneal dystrophy. Am J Ophthalmol 1988;106:65-71.

12. Edward DP, Yue BYJT, Sugar J, Thonar EJ-MA, SundarRaj N, Stock EL, Tso MOM. Heterogeneity in macular corneal dystrophy. Arch Ophthalmol 1988; 106:1579-83.

13. Funderburgh JL, Funderburgh ML, Rodrigues MM, Krachmer JH, Conrad GW. Altered antigenicity of keratan sulphate proteoglycan in selected corneal diseases. Invest Ophthalmol Vis Sci 1990;31:419-28.

14. Klintworth GK, Vogel FS. Macular corneal dystrophy: an inherited acid mucopolysaccharide storage disease of the corneal fibroblast. Am J Pathol 1964;45:565-86.

15. Morgan G. Macular dystrophy of the cornea. Br J Ophthalmol 1966;50:57-67.

16. Teng CC. Macular dystrophy of the cornea. Am J Ophthalmol 1966;62:436-54.

17. Snip RC, Kenyon KR, Green WR. Macular corneal dystrophy: ultrastructural pathology of corneal endothelium and Descemet's membrane. Invest Ophthalmol 1973;12:88-97.

18. François J, Hanssens $M$, Teuchy $H$, Sebruyns $M$. Ultrastructural findings in corneal macular dystrophy (Groenouw II type). Ophthalmic Res 1975;7:80-9.

19. Edward DP, Thonar EJ-MA, Srinivasan M, Yue BYTJ, Tso MOM. Macular dystrophy of the cornea: a systemic disorder of keratan sulphate metabolism. Ophthalmology 1990;97:1194-200.

20. Meek KM, Quantock AJ, Elliott GF, Ridgway AEA, Tullo AB, Bron AJ, Thonar EJ-MA. Macular corneal dystrophy: the macromolecular structure of the stroma observed using electron microscopy and synchrotron X-ray diffraction. Exp Eye Res 1989;49:941-58. 
21. Quantock AJ, Meek KM, Ridgway AEA, Bron AJ, Thonar EJ-MA. Macular corneal dystrophy: reduction in both corneal thickness and collagen interfibrillar spacing. Curr Eye Res 1990;9:393-8.

22. Quantock AJ, Meek KM, Thonar EJ-MA, Assil KK. Synchrotron X-ray diffraction in atypical macular corneal dystrophy. Eye 1993;7:779-84.

23. Capel MS. X12B - a facility for time-resolved X-ray diffraction for biology and macromolecular systems at the NSLS. Sync Rad News 1993;6:22-7.

24. Thonar EJ-MA, Meyer RF, Dennis RF, Lenz ME, Maldonado B, Hassell JR, et al. Absence of normal keratan sulphate in the blood of patients with macular corneal dystrophy. Am J Ophthalmol 1986;102:561-9.

25. Chandrasekhar S, Esterman MA, Hoffman HA. Microdetermination of proteoglycans and glycosaminoglycans in the presence of guaninidine hydrochloride. Anal Biochem 1987;161:103-8.

26. Schwartz DE, Choi Y, Sandell LJ, Hanson WR.Quantitative analysis of collagen, protein and DNA in fixed, paraffin-embedded and sectioned tissue. Histochem J 1985;17:655-63.

27. Scott JE, Orford CR, Hughes EW. Proteoglycancollagen arrangements in developing rat tail tendon. Biochem J 1981;195:573-81.

28. Klintworth GK, Meyer R, Dennis R, Hewitt AT, Stock EL, Lenz ME, et al. Macular corneal dystrophy: lack of keratan sulphate in the serum and cornea. Ophthalmic Paediatr Genet 1986;7:139-43.

29. Thonar EJ-MA, Lenz ME, Klintworth GK, Caterson B, Pachman LM, Glickman P, et al. Quantification of keratan sulphate in blood as a marker of cartilage catabolism. Arthritis Rheum 1985;28:1367-76.

30. Quantock AJ, Meek KM, Thonar EJ-MA. Analysis of high-angle synchrotron X-ray diffraction patterns obtained from macular dystrophy corneas. Cornea 1992;11:185-90.

31. Quantock AJ, Klintworth GK, Schanzlin DJ, Capel MS, Lenz ME, Thonar EJ-MA. Proteoglycans contain a $4.6 \AA$ repeat in macular dystrophy corneas: X-ray diffraction evidence. Biophys J 1996;70:1966-72.

32. Fullwood NJ, Tuft SJ, Malik NS, Meek KM, Ridgway AEA, Harrison RJ. Synchrotron X-ray diffraction studies of keratoconus corneal stroma. Invest Ophthalmol Vis Sci 1992;33:1734-41.

33. Meek KM, Leonard DW. Ultrastructure of the corneal stroma: a comparative study. Biophys J 1993;64:273-80.
34. Quantock AJ, Meek KM, Fullwood NJ, Zabel RW. Scheie's syndrome: the architecture of corneal collagen and distribution of corneal proteoglycans. Can $\mathbf{J}$ Ophthalmol 1993;28:266-72.

35. Rawe IM, Meek KM, Leonard DW, Takahashi T, Cintron C. Structure of corneal scar tissue: an X-ray diffraction study. Biophys J 1994;67:1743-8.

36. Hassell JR, Cintron C, Kublin C, Newsome DA. Proteoglycan changes during restoration of transparency in corneal scars. Arch Biochem Biophys 1983;222:362-9.

37. Ehlers N, Bramsen T. Central thickess in corneal disorders. Acta Ophthalmol (Copenh) 1978;56:412-6.

38. Donnenfeld ED, Cohen EJ, Ingraham HJ, Poleski SA, Goldsmith E, Laibson PR. Corneal thinning in macular corneal dystrophy. Am J Ophthalmol 1986;101:112-3.

39. Quantock AJ, Meek KM. Proteoglycan distribution in the corneas of individuals with bullous keratopathy. Biochem Soc Trans 1990;18:958.

40. Scott JE, Haigh M. Small proteoglycan collagen interactions. Keratan sulphate proteoglycan associates with rabbit corneal collagen fibrils at the 'a' and ' $c$ ' bands. Biosci Rep 1985;5:765-74.

41. Huang Y, Bron AJ, Meek KM, Vellodi A, McDonald B. Ultrastructural study of the cornea in a bone marrow-transplanted Hurler syndrome patient. Exp Eye Res 1996;62:377-87.

42. Fullwood NJ, Meek KM. Synchrotron X-ray studies of changes occurring in the corneal stroma during processing for electron microscopy. J Microsc 1993;169:53-60.

43. Parry DA, Craig AS. Electron microscope evidence for an $80 \AA$ unit in collagen fibrils. Nature 1979;282:213-5.

44. Vogel KG, Trotter JA. The effect of proteoglycans on the morphology of collagen fibrils formed in vitro. Collagen Rel Res 1987:7:105-14.

45. Rada JA, Cornuet PK, Hassell JR. Regulation of corneal collagen fibrillogenesis in vitro by corneal proteoglycan (lumican and decorin) core protein. Exp Eye Res 1993;56:635-48.

46. Klintworth GK, McCracken JS. Corneal diseases. In: Johannessen JV, editor. Electron microscopy in human medicine. New York: McGraw-Hill, 1979:237-66.

47. Fullwood NJ, Davies Y, Nieduszynski IA, Marcyniuk B, Ridgway AEA, Quantock AJ. Cell-surface-associated keratan sulphate on normal and migrating corneal endothelium. Invest Ophthalmol Vis Sci 1996; 37:1256-70. 